\title{
Social cataloguing: an overview for health librarians
}

\author{
Dean Giustini, Daniel Hooker, and Allan Cho
}

[Social cataloguing] allow[s] members to not only share publicly their cataloged inventories, but to post reviews and commentaries on the items posted, create and participate in discussion groups, and tag or classify the items cataloged. In other words, these sites serve as a user-designed, interactive, and shared catalog [1].

\section{Introduction}

This article is an overview of social cataloguing trends for health librarians. Although a number of articles in the literature discuss social bookmarking or folksonomic tagging [2-5], there is a paucity of information about social cataloguing and its relevance for health libraries.

Social cataloguing refers to Web-based applications that allow users to tag and track books and other items in an online inventory or personal filing system [6] (see applications in Appendix A). Social cataloguing sites (SCSs), such as LibraryThing (http://www. librarything.com/) or Shelfari (http://www.shelfari.com/), make it possible for users to catalogue and discuss books with like-minded readers from around the world. In some ways, like other popular Web 2.0 tools such as YouTube (http://www.youtube.com/), Delicious (http://delicious.com/), and SlideShare (http://www. slideshare.net), SCSs facilitate "social discovery" and community collaboration by using tags (user-determined descriptors) to describe books and audiovisual media [6]. Put simply, tags contain information that a user might need to describe or retrieve the item in question and are not limited in number or scope. These descriptors are sometimes displayed in weighted lists as "tag clouds" or concept maps.

With the exception of a few oblique references to the topic, the health library literature is surprisingly silent on the issue of social cataloguing [2,4,7]. A recent general paper in Library Hi Tech, however, looked at the possibility of augmenting the Library of Congress Subject Headings (LCSH) in library catalogues with the tags found in LibraryThing [8]. The authors found instances of concepts expressed as tags in LibraryThing that were missing from the more formal LCSH catalogue description. Their conclusion was that a hybrid system combining LCSH and folksonomic tags would result in richer metadata and, ultimately, a more multifaceted "visual" library catalogue. In terms of navigation and accessibility, this approach would give users the best of both worlds.

As the volume of born-digital articles in biomedicine increases, there is a need to find novel ways to generate metadata for knowledge objects (i.e., scientific articles, books, audiovisual materials, and social media). Do social cataloguing practices hold at least part of the solution to the information glut created by Web 2.0? Tools such as LibraryThing (and even some of the new features in WorldCat) exemplify how principles of the 2.0 era (i.e., user tagging, commenting, and rating systems) can be integrated into catalogues to supplement libraries' descriptive and organizational activities [9]. SCSs may also be critical in tagging articles in blogs and wikis - today's version of grey literature - as well as medical photos and streaming videos archived on various sites.

\section{Attributes and features}

For health librarians interested in using social cataloguing in their libraries, several attributes of SCSs are worth mentioning:

(1) Sharing and creating bibliographies — enhanced ability to share book titles, reviews, and comments (like a book club) with readers from around the world

(2) Building new digital communities — user-centred features are integrated with bibliographic records as a means of inclusive community building

(3) Enhancing findability - library catalogues can be enhanced by social cataloguing practices because they enrich bibliographic and subject metadata [10-14]

D. Giustini. ${ }^{1}$ Gordon and Leslie Diamond Health Care Centre, University of British Columbia, 2775 Laurel Street, Floor 2 ,

Vancouver, BC V5Z 1M9, Canada; and School of Library, Archival and Information Studies (SLAIS), Irving K. Barber Learning Centre, University of British Columbia, 1961 East Mall, Vancouver, BC V6T 1Z1, Canada.

D. Hooker. SLAIS, Irving K. Barber Learning Centre, University of British Columbia, 1961 East Mall, Vancouver, BC V6T 1Z1, Canada.

A. Cho. Irving K. Barber Learning Centre, University of British Columbia, 1961 East Mall, Vancouver, BC V6T 1Z1, Canada.

${ }^{1}$ Corresponding author (e-mail: dean.giustini@ubc.ca). 
For librarians looking to encourage collaboration, implementing social cataloguing features may be a way to perform outreach with users across a potentially worldwide digital network. There is some debate, however, about the value of adding social features to library catalogues and bibliographic records [15-17]. Some authors suggest that SCSs can revitalize the library catalogue by encouraging end-users to tag (and comment on) items while others express concerns that user-generated content, precisely because of its non-expert perspective, may result in confusion for users $[18,19]$.

That said, user-defined content may provide benefits beyond resource discovery and seeing what others read. User tags have the potential to form a meaningful, or semantic, bridge between traditional controlled vocabularies and simple full-text searching, thereby enhancing the search skills of participants. In fact, tagging documents may help to bring about the Semantic Web and the vision of the Internet as "a massive searchable online catalogue" [20]. Health librarians should consider the notion that tagging systems can be applied to library catalogues and can enhance bibliographic searching generally [21] — say, for research-oriented databases such as PubMed and Google Scholar. More research from the perspective of health information retrieval will need to be conducted before the utility of tagging and user-generated content can be fully known.

\section{Social cataloguing Web sites}

The range and number of SCSs are constantly increasing. We would like to present an alphabetical list of some of the most popular tools today for exploration:

(1) aNobii (http://www.anobii.com/; see review at http:// www.appappeal.com/app/anobii/) - Users can share titles, recommendations, and reviews. Build a virtual bookshelf by entering an ISBN or book title, import lists from LibraryThing, Amazon, and Excel spreadsheets. It has approximately 400000 members and is available in 16 languages with data for approximately 12 million books. It even features an iPhone application.

(2) BookArmy (http://www.bookarmy.com/ and see the BookArmy blog at http://thebookarmy.blogspot.com/) Owned by HarperCollins, search across a database containing all English language books with ISBNs. No fees. The exact number of titles is unclear.

(3) Elf (http://www.libraryelf.com/) - Ideal for readers with many library cards from different libraries. Users can consolidate accounts and receive e-mail notifications as items become due or when holds are ready for pickup.

(4) GoodReads (http://www.goodreads.com/; see review at http://www.appappeal.com/app/goodreads/) - Established in 2006, with over 2 million users tracking their reading habits and favourite books. Database contains over 50 million items. Fully featured Facebook application and other social widgets, and no fees.

(5) Google Books - MyLibrary (http://books.google.com/ googlebooks/mylibrary/) - Allows any Google Account user to search, save, annotate, rate, and review any text available through Google Books (http://books. google.com/). Sample collections from other users are also featured on the MyLibrary home page.

(6) GuruLib (http://www.gurulib.com/) - A way to track books, DVDs, games, software, and movies. It allows users to search libraries worldwide to collect information about hard to find items using the ANSI/NISO Z39.50 protocol.

(7) LibraryThing (http://www.librarything.com/; see review at http://www.appappeal.com/app/librarything/ and the LibraryThing blog at http://www.librarything.com/blog/) A leader in social cataloguing. Users are "thingamabrarians", who post reading lists and book reviews, and chat with other users. Search Amazon, the Library of Congress, or dozens of other catalogues for access to book data. Use the Dewey Decimal Classification System or the Library of Congress classification system to list your books either publicly or privately. It has 850000 users and approximately 44 million books catalogued.

(8) Shelfari (http://www.shelfari.com/; see review at http://www.appappeal.com/app/shelfari/ and the Shelfari blog at http://shelfari.typepad.com/) - Acquired by Amazon in 2008, Shelfari lets users create virtual "bookshelves" of titles. Users can rate, review, tag, and discuss their books. It offers Wordpress and other blog integration along with standard social networking features.

\section{Criticism}

A scan of the literature and discussion on the blogosphere illustrates a variety of opinions about SCSs. Concerns about their informal structure and inconsistent language usage are among the most commonly cited problems in unmoderated indexing environments. Though insight from users and the flexibility of free association are important facets of this new technology, the lack of authority control and increased possibility for bias in natural language are particularly cause for concern. The following list explains the most common issues in more depth:

(i) SCSs generally lack formal hierarchical structures Tags are created in isolation and establish no hierarchical relationships among terms. In the MESH thesaurus for example, "Vitamins" is listed under or as a type of "Micronutrients" and has a narrower concept, "Vitamin B Complex". These terms are linked in the vocabulary and provide different levels of specificity for improved information retrieval and resource collocation. In tagging, however, the tags are not inter-related that way, meaning users must include both the broad and narrow tags to achieve meaningful levels of description.

(ii) SCSs often do not discriminate between plural and singular forms of words - Does the vocabulary use "Disease" or "Diseases"? In tagging systems, you have to search both plural and singular forms of concepts.

(iii) SCSs contain all kinds of unorthodox spellings and terminologies - Freedom of language introduces inconsistent or inappropriate usage and variant spellings that clutter description and degrade collocation of similar items. 
(iv) SCSs do not sufficiently distinguish between synonyms Two terms that express the same concept are not standardized. Controlled vocabularies have "authority files" that dictate a preferred way of expressing a single concept, for example, using either "Swine Flu" or "H1N1". In a tagging environment, there is no such control over synonymous terms.

(v) Open tagging in SCSs results in conceptual ambiguity or "polysemes" - Conceptual ambiguity in language can lead to low search precision when using tags. For example, the concept of "cold" has many connotations in medicine: the "common cold" as in a respiratory infection, or "cold" as in body temperature, or "COLD" (chronic obstructive lung disease). Without conceptual control, ambiguous terms produce all kinds of false drops during information retrieval.

(vi) SCSs may encourage malicious intent in language usage Unchecked opinion or bias may be added in tagged content, particularly if there are strong feelings evoked by certain subjects, HIV/AIDS or cancer being salient examples. Tags can be moderated for particularly harmful content, but that takes valuable time and human resources [22].

\section{OPAC 2.0: next generation catalogue?}

In 2006, during a period of fervent interest in Library 2.0, there was debate about embedding social features in library Web sites and online public access catalogues (OPACs) [23]. Pockets of innovation began to appear in library catalogues, but a broader adoption of social cataloguing principles has been slower to arrive [24]. Some studies comparing tagging with subject indexing in OPACs raise several issues of concern but do not provide sufficient direction to librarians [25]. Some librarians say that folksonomies cannot replace well-established controlled vocabularies, while others believe that tagging may help to change user attitudes toward library OPACs, by potentially making them "more fun" [26,27].

In a bold move to draw on the usefulness of LibraryThing, the Claremont University Libraries, an academic library consortium in the United States, integrated several social features into their union catalogue through participation in a project entitled LibraryThing for Libraries (LTFL) [28]. For health libraries considering the use of LibraryThing as a catalogue overlay, as well as for libraries interested in learning about next generation cataloguing concepts, this 2009 article provides a good starting point. (For a list of health libraries using LibraryThing, see Appendix B.)

The idea of a "next-generation" OPAC is catching on in Canadian libraries. For just two examples, look at the Edmonton Public Library catalogue [29] and the new "Primo" version of the University of British Columbia Library's catalogue (in testing Fall 2009) [30]. In the United States, PennTags (http://tags.library.upenn.edu/) at the University of Pennsylvania Library allows users to mark up library records with tags and save them within a unique portal of resources. The impulse to improve library catalogues has also led to the development of several often open source cataloguing systems. One tool called Scriblio (http://about.scriblio.net/) operates on the Wordpress.org blogging platform [31]. A similar project that permits tagging, rating, and reviewing is
SOPAC, the social OPAC (http://thesocialopac.net/), which has been installed in a small number of Canadian and American public and special libraries. VuFind is yet another catalogue search tool (called a "catalogue overlay") that integrates traditional OPAC services with many of the features found in other systems described here [32].

Another product generating interest in aggregated Web 2.0 content is LibGuides, which can be used to create customized, subject-specific resource guides. These guides integrate information and library services for distribution outside the library home page to "connect with patrons wherever they are" [33]. Although not meant to disseminate catalogue content exclusively, LibGuides are unique in combining folksonomic tags and Web sites with recommended library content. (For a list of libraries using LibGuides, see the SpringShare Library Web site [34].)

\section{Conclusion}

Social cataloguing holds considerable promise for the enhancement of health library services. Health librarians are advised to explore the SCSs discussed in this article and consider building user interactivity into their OPACs. While SCSs help to build global online communities, they also encourage collaboration and communication between units within a single health library (i.e., public and technical services). For those interested in integrating social features into online catalogues, keep in mind that this can be done simply and incrementally.

The future of automated subject cataloguing and indexing through data extraction in the biomedical literature should include culling information from social cataloguing sites. Even though SCSs have been around for some time, they are finally beginning to gain interest and acceptance. Our goal as health librarians should be to make the library's catalogue as useful as possible while promoting discoverability. The cultivation of vibrant community participation and the potential for trust building between the library and its users made through social cataloguing practices may pay dividends for health libraries and our user groups well into the future.

\section{References}

1. Spiteri LF. The impact of social cataloging sites on the construction of bibliographic records in the public library catalog. Cataloging \& Classification Quarterly. 2009;47(1):52-7.

2. Barsky E, Purdon M. Introducing web 2.0: social networking and social bookmarking for health librarians. J Can Health Libr Assoc. 2006;27(3):65-7.

3. Barsky E, Cho A. Introducing web 2.0: social search for health librarians. J Can Health Libr Assoc. 2007;28(2):59-61.

4. Boulos M, Wheeler S. The emerging Web 2.0 social software: an enabling suite of sociable technologies in health and health care education. Health Info Libr J. 2007;24(1):22-3.

-5. Maggio L, Bresnahan M, Flynn D, Harzbecker J, Blanchard M, Ginn D. A case study: using social tagging to engage students in learning Medical Subject Headings. J Med Libr Assoc. 2009 Apr;97(2):77-83. 
-6. Mendes, L.H., Quiñonez-Skinner, J. and Skaggs, D. Subjecting the catalog to tagging. Libr Hi Tech. 2009;27(1):30-41.

7. Bianco CE. Medical librarians' uses and perceptions of social tagging. J Med Libr Assoc. 2009 Apr;97(2):136-9.

8. Thomas M, Caudle D, Schmitz C. To tag or not to tag? Libr Hi Tech. 2009;27(3):411-31.

9. Wenzler J. LibraryThing and the library catalog: adding collective intelligence to the OPAC. A Workshop on Next Generation Libraries. San Francisco State University CARL NITIG [homepage on the Internet]. 2007 Sept 7 [cited 2009 Oct 19]. Available from: http://online.sfsu.edu/\%7Ejwenzler/research/ LTFL.pdf.

10. Hanson C. Discoverability Phase 1 Final Report of the Web Services Steering Committee at the University of Minnesota Libraries 2009 [homepage on the Internet]. Minneapolis: University of Minnesota; 2009 [cited 2009 Oct 19]. Available from: http://conservancy.umn.edu/bitstream/48258/3/ DiscoverabilityPhase1Report.pdf.

11. Steele T. The new cooperative cataloging. Libr Hi Tech. 2009;27(1):68-77.

12. Smith G. Tagging: people-powered metadata for the social web. Berkeley: New Riders; 2007.

13. Rolla P. User tags versus subject headings: can user-supplied data improve subject access to library collections? Libr Resour Tech Serv. 2009;53(3):174-84.

14. Tonkin E, Corrado E, Moulaison H, Kipp M, Resmini A, Pfeiffer D, Zhang Q. Collaborative and social tagging networks. Ariadne. 2008 Feb;(54) [cited 2009 Oct 19]. Available from: http://www.ariadne.ac.uk/issue54/tonkin-et-al.

15. Sierra T, Ryan J, Wust M. Beyond OPAC 2.0: library catalog as versatile discovery platform. Code4Lib Journal [serial on the Internet]. 2007;(1) [cited 2009 Oct 19]. Available from: http://journal.code4lib.org/articles/10.

16. Bullen A. The 'long tale': using web 2.0 concepts to enhance digital collections. Comput Libr. 2008;28(9):31-5.

17. Macgregor G, McCullock E. Collaborative tagging as a knowledge organization and resource discovery tool. Libr Rev. 2006;55(5):291-300.

18. Calhoun K. The changing nature of the catalog and its integration with other discovery tools. Report to the Library of Congress [homepage on the Internet]. Washington: Library of Congress; 2006 Mar 17 [cited 2009 Oct 19]. Available from: http://www.loc.gov/catdir/calhoun-report-final.pdf.

19. Fister B. LibraryThing for academic libraries. ACRLog Association of Academic \& College Research Libraries, Blogging by and for Academic \& Research Librarians. 2008 Mar 8 [cited 2009 Oct 19]. Available from: http://www.acrlog.org/ 2008-03-08/library-thing-for-academic-libraries.

20. Cho A, Giustini D. The semantic web as a large, searchable catalogue: a librarian's perspective. The Semantic Universe [serial on Internet]. 2007 Oct [cited 2009 Oct 19]. Available from: http://www.semanticuniverse.com/articles-semanticweb-large-searchable-catalogue-librarian $\% \mathrm{E} 2 \% 80 \%$

99s-perspective.html.
21. Kozel-Gains M, Stoddard R. Experiments and experiences in liaison activities: lessons from new librarians in integrating technology, face-to-face, and follow-up. Collections Management. 2009;34(2):130-42.

22. Spiteri LF. The structure and form of folksonomy tags: the road to the public library catalog. Inform Tech Libr. 2007;26(3):13-25.

23. Blyberg J. 2006: Year of the phoenix OPAC? blyberg.net: A library Geek Blog. 2006 Aug 2 [cited 2009 Oct 19]. Available from: http://www.blyberg.net/2006/02/08/2006-year-of-thephoenix-opac/.

24. Dempsey L. Always on: libraries in a world of permanent connectivity. First Monday. 2009;14:1-5 [cited 2009 Oct 19]. Available from: http://www.uic.edu/htbin/cgiwrap/bin/ ojs/index.php/fm/article/viewArticle/2291/2070.

25. Casey M. Looking toward catalog 2.0. In: Courtney N, editor. Library 2.0 and beyond: innovative technologies and tomorrow's user. Westport: Libraries Unlimited; 2007.

26. Kome SH. Hierarchical subject relationships in folksonomies [MLIS thesis]. Chapel Hill: University of North Carolina; 2005 [cited 2009 Oct 12]. Available from: http://etd.ils.unc. edu:8080/dspace/bitstream/1901/238/1/samkome.pdf.

27. Spalding T. Is your OPAC fun? (a manifesto of sorts). Thing-ology Blog: Meaning, methods and debate [weblog]. 2006 Dec 4 [cited 2009 Oct 19]. Available from: http:// www.librarything.com/thingology/2006/12/is-your-opac-funmanifesto-of-sorts.php.

28. Westcott J, Chappell A, Lebel C. LibraryThing for libraries at Claremont. Libr Hi Tech. 2009;27(1):78-81.

29. Edmonton Public Library catalogue [homepage on the Internet] [cited 2009 Oct 19]. Available from: http://epl. bibliocommons.com/dashboard.

30. UBC Library Catalogue "Primo" testing site [homepage on the Internet] [cited 2009 Oct 19]. Available from: http://search.library.ubc.ca/primo_library/libweb/action/ search.do?vid=UBC\&fromLogin=true.

31. Smith G. Tagging: people-powered metadata for the social web. Berkeley: New Riders; 2007.

32. Ho B, Kelley K, Garrison S. Implementing VuFind as an alternative to Voyager's WebVoyage interface: One library's experience. Libr Hi Tech. 2009;27(1):82-92.

33. Corrado E. Delicious subject guides: maintaining subject guides using a social bookmarking site. In Partnership: The Canadian Journal of Library and Information Practice and Research [serial on the Internet]. 2008;3(2) [cited 2009 Oct 19]. Available from: http://journal.lib.uoguelph.ca/index.php/ perj/article/view/328/1375.

34. SpringShare Library/library 2.0 website [homepage on the Internet] [cited 2009 Oct 19]. Available from: http://libguides. com/community.php?m=i\&ref=community.libguides.com. 


\section{Appendix A}

Table A1. New and emerging social cataloguing sites.

\begin{tabular}{|c|c|}
\hline Backloggery & http://www.backloggery.com/ \\
\hline Bibliophil & http://www.bibliophil.org/ \\
\hline Bookjetty & http://www.bookjetty.com/ \\
\hline ChainReading & http://www.chainreading.com/ \\
\hline ConnectViaBooks & http://www.connectviabooks.com/ \\
\hline Discogs & http://www.discogs.com/ \\
\hline Douban (Chinese only) & http://www.douban.com/ \\
\hline Flixstter & http://www.flixster.com/ \\
\hline Internet Archive & http://www.archive.org/index.php \\
\hline Jumper 2.0 & http://www.jumpernetworks.com/ \\
\hline Last.fm & http://www.last.fm/ \\
\hline Lib.rario.us & http://lib.rario.us/ \\
\hline Listal & http://www.listal.com/ \\
\hline LivingSocial.com & $\overline{\mathrm{http}: / / \text { livingsocial.com/ }}$ \\
\hline Lulu & http://www.lulu.com/ \\
\hline MediaChest & http://www.mediachest.com/ \\
\hline MobyGames & http://www.mobygames.com/home \\
\hline MyEbook & http://www.myebook.com/ \\
\hline Rate Your Music & http://rateyourmusic.com/ \\
\hline Reader2 & http://reader2.com/ \\
\hline Stashmatic & http://www.stashmatic.com/ \\
\hline Stuffopolis & http://www.stuffopolis.com/wopr/index.php \\
\hline WorldCat & http://www.worldcat.org/ \\
\hline WeRead & http://weread.com/ \\
\hline ulike.net & http://www.ulike.net/ \\
\hline
\end{tabular}

\section{Appendix B}

Table B1. Health libraries using LibraryThing for Libraries.

\begin{tabular}{|c|c|}
\hline $\begin{array}{l}\text { Blessing Health Professions Library, } \\
\text { Blessing-Rieman College of Nursing } \\
\text { (Quincy, Ill., USA) }\end{array}$ & $\frac{\text { http://www.librarything.com/venue/47389/Blessing-Health-Professions-Library--- }}{\underline{\text { Blessing-Rieman-College-of-Nursing }}}$ \\
\hline $\begin{array}{l}\text { DeArmond Consumer Health Library } \\
\text { (Coeur d'Alene, Idaho, USA) }\end{array}$ & http://www.librarything.com/venue/47236/DeArmond-Consumer-Health-Library \\
\hline $\begin{array}{l}\text { Delaware Division of Substance Abuse \& } \\
\text { Mental Health (New Castle, Del., USA) }\end{array}$ & $\frac{\mathrm{http}: / / \text { www.librarything.com/venue/45881/ }}{\underline{\text { Delaware-Division-of-Substance-Abuse-\%26-Mental-Health }}}$ \\
\hline $\begin{array}{l}\text { Malmo University Health Society Library } \\
\text { (Malmo, Sweden) }\end{array}$ & $\frac{\text { http://www.librarything.com/venue/47217/Biblioteket-Hälsa-och-samhälle-\%28Health- }}{\text { \%26-Society-Library\%29---Malmö-högskola-\%28Malmo-University\%29 }}$ \\
\hline $\begin{array}{l}\text { Malmo University Oral Health Library } \\
\text { (Malmo, Sweden) }\end{array}$ & $\frac{\text { http://www.librarything.com/venue/47218/Odontologiska-biblioteket-\%28Oral-Health- }}{\underline{\text { Library\%29---Malmö-högskola-\%28Malmo-University\%29 }}}$ \\
\hline
\end{tabular}


Table B2. Health libraries on LibraryThing.

Cooper University Health Resource Center (Camden, N.J., USA)

Gunderson Lutheran Health Sciences Library

(LaCrosse, Wis., USA)

Leddy Library, Schulich School of Medicine \& Dentistry, University of Western Ontario (London, Ont., Canada)

Lister Hill Library of the Health Sciences, University of

Alabama at Birmingham (Alabama, USA)

Mental Health Rights Coalition (Hamilton, Ont., Canada)

Northeastern Vermont Regional Hospital Library

(St. Johnsbury, Vt., USA)

Physician Health Program of British Columbia (Vancouver, B.C., Canada)

Samaritan Medical Center Library (Watertown, N.Y., USA)

Quest Center for Integrative Health (Portland, Oreg., USA)

Tuality Health Science Library (Hillsboro, Oreg., USA)

UBC Biomedical Branch Library, University of British

Columbia (Vancouver, B.C., Canada)

Washington State University Animal Health Library

Windham Hospital Library (Willimantic, Conn., USA)

Women's Health Care Centre (Peterborough, Ont., Canada) http://www.librarything.com/profile/cooperhealthresource

http://www.librarything.com/profile/glhealthscilibrary

http://www.librarything.com/profile/leddymedical

$\underline{\text { http://www.librarything.com/profile/ListerHillLibraryNew }}$

http://www.librarything.com/profile/MHRC

http://www.librarything.com/profile/NVRHLibrary

http://www.librarything.com/profile/BCPhysicianhealth

http://www.librarything.com/profile/smclibrary http://www.librarything.com/profile/QuestCenter http://www.librarything.com/profile/TualityLibrary http://www.librarything.com/profile/bmblib

http://www.librarything.com/profile/WSU_Anim_Health_Lib http://www.librarything.com/profile/wcmhlibrary http://www.librarything.com/profile/WomensHealthPtbo 